\title{
Application of FEM in Investigating Machining Performance
}

\author{
Hendri Yanda ${ }^{1, a}$, Jaharah A. Ghani ${ }^{2, b}$, Che Hassan Che Haron ${ }^{3, c}$ \\ 1,2,3 Department of Mechanical and Materials Engineering, \\ Faculty of Engineering and Built Environment, Universiti Kebangsaan Malaysia, \\ Bangi, Selangor Darul Ehsan, 43600 Malaysia \\ ${ }^{a}$ Hyanda@eng.ukm.my, ${ }^{b}$ jaharah@eng.ukm.my, ${ }^{c}$ chase@eng.ukm.my
}

Keywords: Finite element method, machining performance, rake angle, clearance angle.

\begin{abstract}
The two biggest problems that often experienced in machining cast iron are poor machinability and high hardness. Up to now, many researchers have investigated machining performance and how to find optimum condition in machining ductile cast iron. This study aims to investigate the machining performance of ductile cast iron and carbide cutting tool using FEM. Performances were evaluated by changing the cutting tool geometries on the machining responses of cutting force, stress, strain, and generated temperature on the workpiece. Deform-3D commercial finite element software was used in this study. Ductile cast iron FCD 500 grade was used as the work piece material and carbide insert DNMA432 type with WC (Tungsten) was used for the cutting tool. The effects of rake and clearance angles were investigated by designing various tool geometries. Various combination of carbide insert geometries were designed using Solid Work to produce $+15,+20$ and $+30 \mathrm{deg}$ for rake angle and 5, 7, 8 and 9 deg for clearance angle. Machining condition for the simulations were remained constant at cutting speed of $200 \mathrm{~m} / \mathrm{min}$, feed rate of $0.35 \mathrm{~mm} / \mathrm{rev}$, and depth of cut of $0.3 \mathrm{~mm}$. The results of effective-stress, strain and generated temperature on both chip and material surface were analysed. The results show that by increasing the rake angle $(\alpha)$, it will improves the machining performance by reducing the cutting force, stress, strain and generated temperature on surface of workpiece. But, by increasing the clearance angle $(\gamma)$, it will not affect much to the cutting force, stress, strain and generated temperature on chip.
\end{abstract}

\section{Introduction}

Finite Element Analysis (FEA) technique was the first introduced in 1960s and still widely used for analysis such as in tools design and forming processes. Based on the success of FEM simulations for bulk forming processes, many researchers developed their own FEM codes to analyze metal cutting processes during the early 1980s up to now [1], [2], [3], [4] and [5]. Cerenitti et al. [1] assumed a rigid sharp tool and elasto-plastic workpiece, and defined a node separation criterion based on the geometry of the element approaching the cutting edge. Cerenitti et al. [1] used an early version of a commercial implicit FEM code "DEFORM-2D"TM". This code uses four-node quadrilateral elements and is based on static Lagrangian formulation. Today, DEFORM-3D ${ }^{\mathrm{TM}}$ code is commonly used by researchers and industry in machining simulation [6].

Applications of FEM models for machining can be divided into six groups: 1) tool edge design, 2) tool wear, 3) tool coating, 4) chip flow, 5) burr formation and 6) residual stress and surface integrity. The direct experimental approach to study machining processes is expensive and time consuming. For solving this problem, the finite element methods are most frequently used. Modeling tool wear using FEM has advantages over conventional statistical approach because it requires less experimental effort and it provides useful information such as deformations, stresses, strain and temperature in chip and the workpiece, as well as the cutting force, tool stress and temperature on the tool working under specific cutting parameter [7]. This paper presents the application of FEM in studying the effect of tool geometries in turning ductile cast iron FCD 500 on the machining performance of cutting force, stress, strain, and generated temperature. 


\section{Methodology}

Orthogonal Cutting Condition Model. One of the important parameters in the orthogonal metal cutting process is the rake angle between the face of the cutting tool and the plane perpendicular to the cutting direction. The magnitudes of tool cutting geometries have significant effects on the performance of the cutting tool and the integrity of the cut surface. The main objective of this research is to apply the finite element method to study the rake angle and clearance effects in orthogonal metal cutting of ductile cast iron with continuous chip formation, while the other machining parameters of cutting speed, feed rate and depth of cut were kept constant. Finite element simulation results of the orthogonal metal cutting using three sets of perfectly sharp cutting tools with positive rake angles of 15,20 and $30^{\circ}$ and four clearance angles of 5, 7, 8 and 9 respectively. The commercial software Deform-3D for deformation analysis was used to simulate orthogonal metal cutting process. It is based on an updated Lagrangian formulation and employs an implicit integration scheme. Fig. 1 shows the schematic of orthogonal cutting condition model.

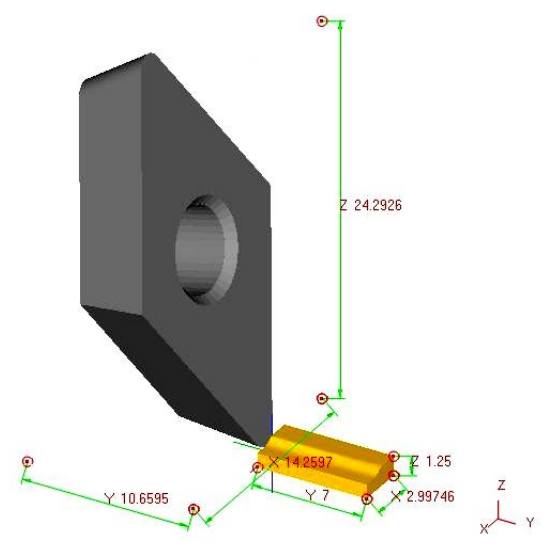

Fig. 1 Schematic of orthogonal cutting condition model

Parameter Inputs and Cutting Conditions. The three-dimensional finite element model was generated under a plane strain assumption because the width of cut was larger than the undeformed chip thickness in this orthogonal cutting arrangement. The flow stress behavior of the work material and the contact conditions were used as equation for flow stress $\sigma$ models, $\sigma=\sigma_{1} \varepsilon^{n} \quad$ [8]. Cutting conditions are predefined are shown in Table 1.

Table. 1: Parameter inputs in the simulation process

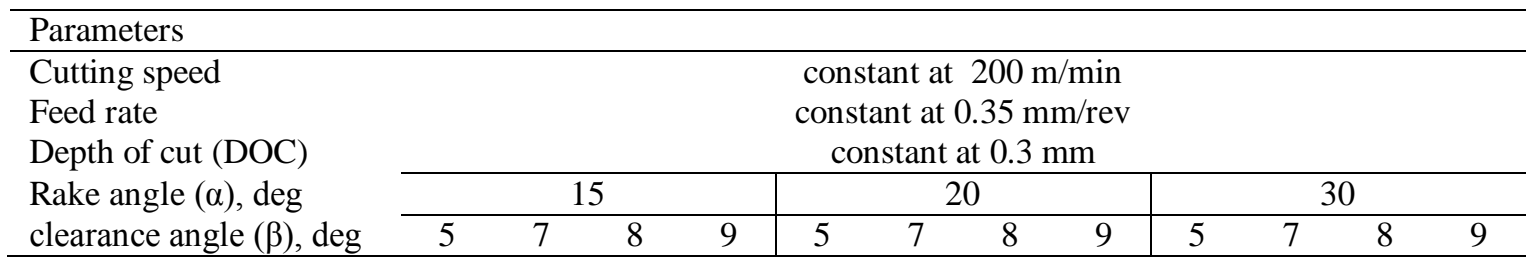

The workpiece material was ductile cast iron FCD500 grade. This material was selected as the workpiece material in this study because it was widely used in automotive application. Deform-3D software was used to simulate the effect of tool cutting geometries in turning ductile cast iron using uncoated carbide cutting tool. The simulations were performed by changing the rake angle and clearance angle while the cutting speed, feed rate and depth of cut were kept constant at $200 \mathrm{~m} / \mathrm{min}$, $0.35 \mathrm{~mm} / \mathrm{rev}$ and $0.3 \mathrm{~mm}$ respectively. The simulation results of cutting force, effective-stress, strain and generated temperature on the workpiece surface were studied and analyzed. The operation is simulated using insert carbide of DNMA432 type that has a nose angle of 55 deg and without the use of coolant. The tool was defined to be a rigid body which considers thermal transfer 
for modeling the cutting temperature field. Cutting condition, simulation models and material properties of carbide cutting tool and workpiece are shown in Table 2.

Table 2: Cutting condition to the simulation models and material properties

\begin{tabular}{lc}
\hline Tool geometry of DNMA 432 & \\
\hline Side Cutting Edge Angle (SCEA), deg & -3 \\
Back Rack angle (BR), deg & -5 \\
Side Rack angle (SR), deg & -5 \\
Nose angle, deg & 55 \\
\hline Tool properties (WC as base material, uncoated carbide tool) & \\
\hline Modulus young (GPa) & 650 \\
Thermal expansion & $5 \mathrm{e}-06$ \\
Poison ratio & 0.25 \\
\hline Boundary condition & 20 \\
\hline Initial temperature, deg. C & 0.6 \\
Shear friction factor & 45 \\
Heat transfer coefficient at the interface, $\mathrm{N} / \mathrm{s} \mathrm{mm}^{\circ} \mathrm{C}$ & \\
\hline Workpiece geometry & 0.3 \\
\hline Depth of cut, mm & 3.4 \\
Width of cut, mm & 7 \\
Length of workpiece, mm & \\
\hline Workpiece properties $(\mathrm{Ductile}$ cast iron $\mathrm{FCD} 500)$ & 169 \\
\hline Modulus elasticity $(\mathrm{GPa})$ & 35.2 \\
Thermal conductivity $\left(\mathrm{W} / \mathrm{m} .{ }^{\circ} \mathrm{C}\right)$ & 12.5 \\
Thermal expansion coefficient $\left(\cdot 10^{-6}{ }^{\circ} \mathrm{C}^{-1}\right.$ ) & 3.7 \\
Heat capacity (N/mm $\left.{ }^{\circ} \mathrm{C}\right)$ & 0.95 \\
Emissivity &
\end{tabular}

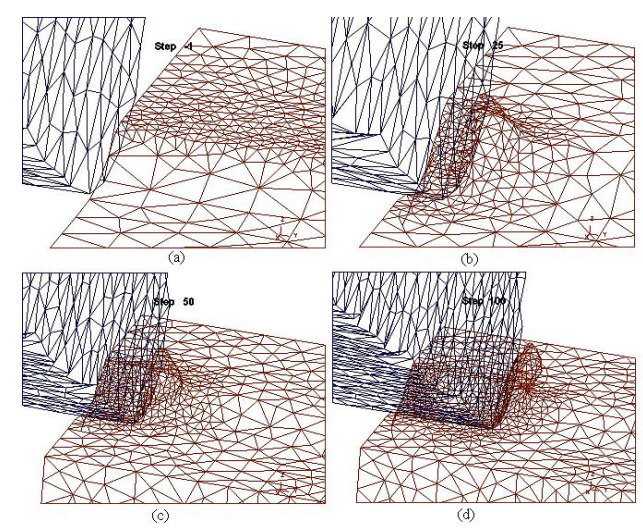

Fig. 2 (a) Initial mesh and tool indentation, (b) Chip formation at step 25,

(c) Chip formation at step 50, (d) Developed continues chip at step 100.

Displacement, shape and surface mesh of the tool and workpiece at the initial mesh of beginning the cutting operation was developed until chip formation reach step 100 as illustrated in Fig. 2a, 2b, $2 \mathrm{c}$ and $2 \mathrm{~d}$ respectively. The workpiece and the tool are characteristized by non uniform mesh distribution in the simulation. Very small element is required in the contact area between tool and workpiece because of very large temperature gradient and stress that will develop in this region during the simulation.

Design of Cutting Tool Geometries. Cutting tools were designed for various rake angles of +15 , +20 and $+30 \mathrm{deg}$ and the clearance angles of 5, 7,8 and $9 \mathrm{deg}$. There are twelve combinations of geometry designs for carbide tool using Solid Work software as shown in Fig 3. 


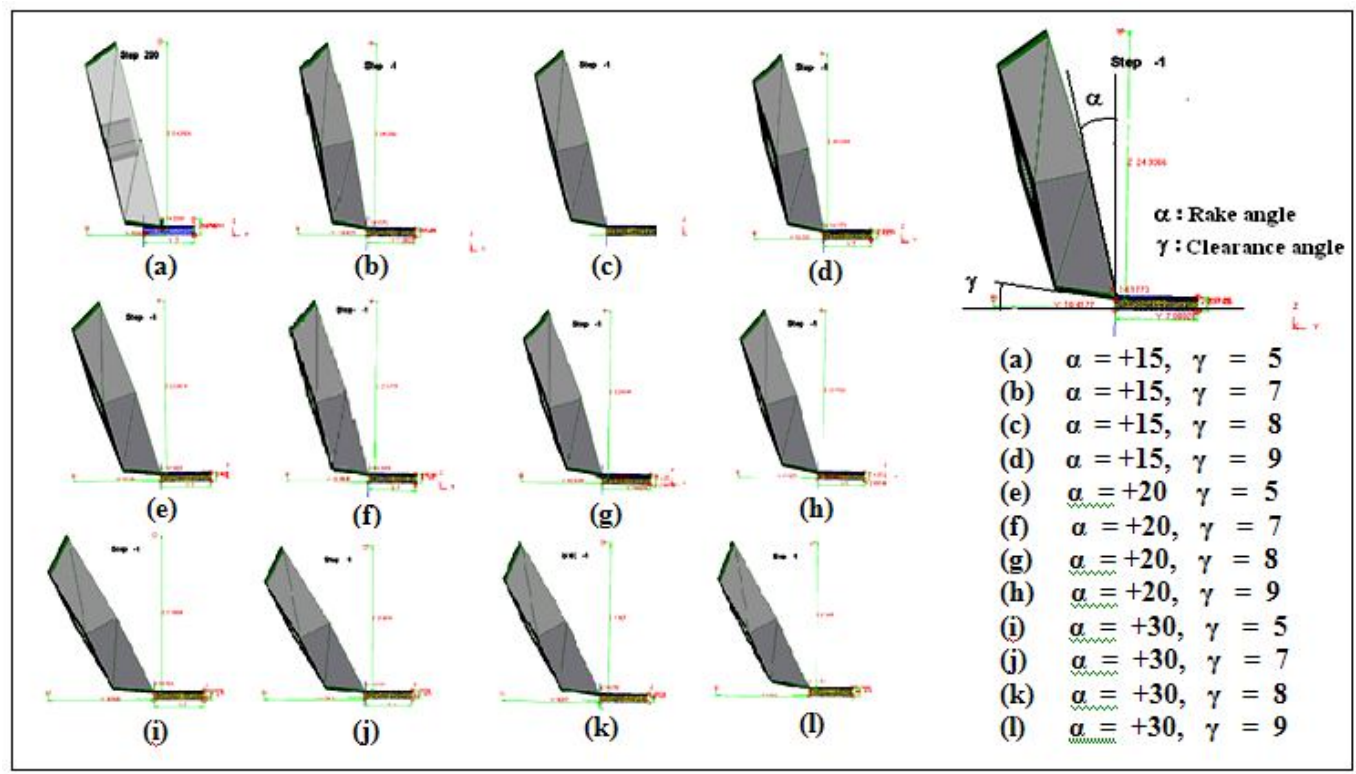

Fig. 3 Modeling for 12 combinations of geometry designs of rake and Clearance angle for DNMA carbide tool cutting

\section{Simulation Results and Discussion}

Primary and Secondary Deformation Zone. Fig. 4 shows the simulation results for displacement, cutting force, effective stress, strain and generated temperature for rake angle of +20 deg and clearance angle of $5 \mathrm{deg}$ (cutting speed of $200 \mathrm{~m} / \mathrm{min}$, feed rate of $0.35 \mathrm{~mm} / \mathrm{rev}$ and DOC of $3 \mathrm{~mm}$ )

The biggest displacement was reached around $2.84 \mathrm{~mm}$ in total displacement at the end of chip formation (Fig. 4a). The biggest deformation was occurred on the primary deformation zone, followed by the secondary deformation zone. This also causes higher stress occurred on this area, about $3565 \mathrm{MPa}$ in primary shear zone (Fig.4b). These results are agreeable with Kalhori [9], where the major deformation during cutting process were concentrated in two region close to the cutting tool edge, and the bigger deformation were occurred in the primary deformation zone, followed by secondary deformation zone, sliding region and sticking region.

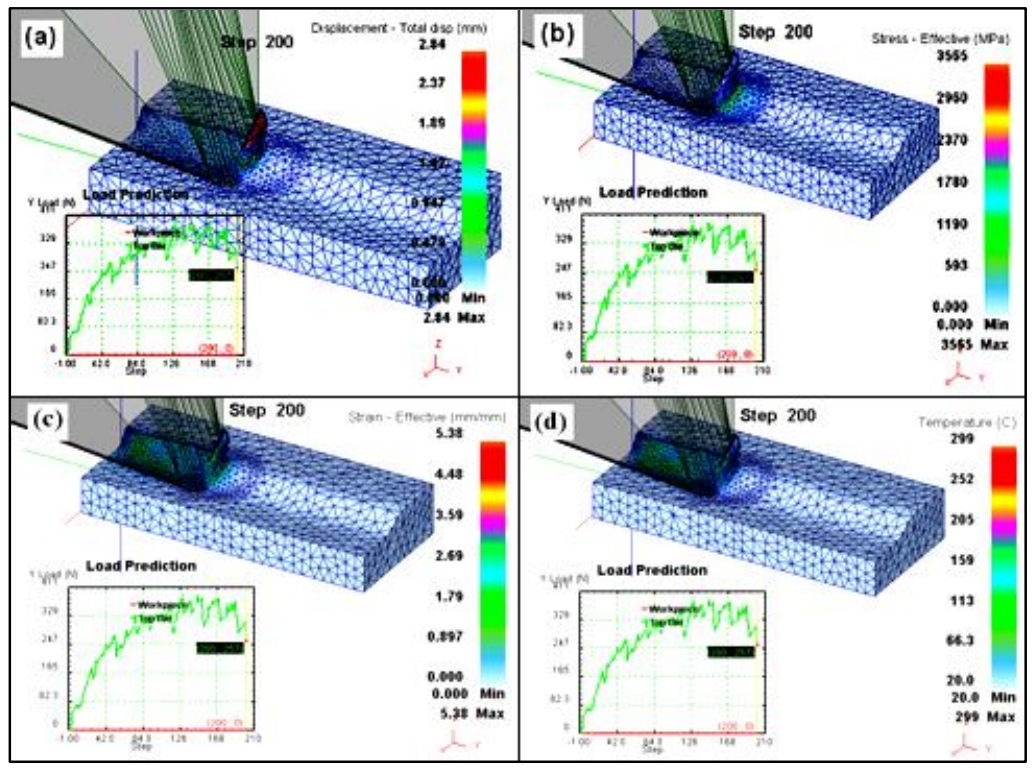

Fig. 4 Simulation results for cutting speed of $200 \mathrm{~m} / \mathrm{min}$, rake angle of +20 deg and clearance angle of $5 \mathrm{deg}$ ), a) Displacement, b) Effective stress, c) Effective Strain and c) Generated temperature. 
Fig. 4c shows the highest effective strain occurred on primary shear zone about $5.03 \mathrm{~mm} / \mathrm{mm}$, and then followed by secondary shear zone about less than $2.69 \mathrm{~mm} / \mathrm{mm}$. And, the highest temperature was occurred at sliding region on primary shear zone around $299{ }^{\circ} \mathrm{C}$ as shown in Fig $4 \mathrm{~d}$. Table 3 shows the simulation results for all various rake and clearance angle where cutting speed, feed rate and depth of cut (DOC) that were kept constant at $200 \mathrm{~m} / \mathrm{min}, 0.35 \mathrm{~mm} / \mathrm{rev}$ and $3 \mathrm{~mm}$ respectively.

Table 3: The result of simulation for cutting force, stress, strain, and temperature

\begin{tabular}{cccccccccc}
\hline No & $\begin{array}{c}\text { Rake } \\
\text { angle }[\boldsymbol{\alpha}]\end{array}$ & $\begin{array}{c}\text { Clearance } \\
\text { Angle }[\boldsymbol{\beta}]\end{array}$ & $\begin{array}{c}\text { Cutting Speed } \\
{[\mathbf{m} / \mathbf{m i n}]}\end{array}$ & $\begin{array}{c}\text { Feed } \\
{[\mathbf{m m} / \mathbf{r e v}]}\end{array}$ & $\begin{array}{c}\text { DOC } \\
{[\mathbf{m m}]}\end{array}$ & $\begin{array}{c}\text { Cutting } \\
\text { Force }[\mathbf{N}]\end{array}$ & $\begin{array}{c}\text { Stress } \\
{[\mathbf{M P a}]}\end{array}$ & $\begin{array}{c}\text { Strain } \\
{[\mathbf{m m} / \mathbf{m m}]}\end{array}$ & $\begin{array}{c}\text { Temp } \\
{\left[{ }^{\mathbf{0}} \mathbf{C}\right]}\end{array}$ \\
\hline 1 & +15 & 5 & 200 & 0.35 & 3 & 346 & 4320 & 6.11 & 321 \\
2 & +15 & 7 & 200 & 0.35 & 3 & 347 & 4230 & 6.56 & 318 \\
3 & +15 & 8 & 200 & 0.35 & 3 & 400 & 4195 & 6.24 & 334 \\
4 & +15 & 9 & 200 & 0.35 & 3 & 402 & 4340 & 7.13 & 304 \\
\hline 5 & +20 & 5 & 200 & 0.35 & 3 & 239 & 3565 & 5.03 & 299 \\
6 & +20 & 7 & 200 & 0.35 & 3 & 295 & 3690 & 4.96 & 304 \\
7 & +20 & 8 & 200 & 0.35 & 3 & 271 & 3690 & 5.56 & 272 \\
8 & +20 & 9 & 200 & 0.35 & 3 & 297 & 3720 & 5.65 & 263 \\
\hline 9 & +30 & 5 & 200 & 0.35 & 3 & 165 & 3360 & 4.31 & 198 \\
10 & +30 & 7 & 200 & 0.35 & 3 & 178 & 3540 & 4.45 & 206 \\
11 & +30 & 8 & 200 & 0.35 & 3 & 196 & 3537 & 5.07 & 218 \\
12 & +30 & 9 & 200 & 0.35 & 3 & 262 & 3400 & 4.68 & 225 \\
\hline
\end{tabular}

The Effect of Rake Angle ( $\boldsymbol{\alpha})$. By increasing the rake angle, effect on the cutting force, stress, strain and generated temperature are decreasing as shown in Fig. 5a, 5b, 5c and 5d respectively. For example, increasing the rake angle from $+15 \mathrm{deg}$ to $+20 \mathrm{deg}$, will reduce the cutting force from 346 $\mathrm{N}$ to $239 \mathrm{~N}$, stress from $4320 \mathrm{MPa}$ to $3565 \mathrm{MPa}$, strain from 6.11 to $5.03 \mathrm{~mm} / \mathrm{mm}$ and temperature from $321{ }^{\circ} \mathrm{C}$ to $299^{\circ} \mathrm{C}$. This can be accepted that the reducing in cutting force, stress, strain and temperature were resulted from reduction of tool/chip contact area, so the cutting force and friction are expected to be decreased. This is agreeable with theory and experiment done by Gunay et al [10].

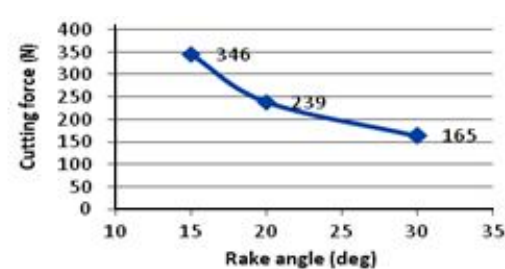

(a)

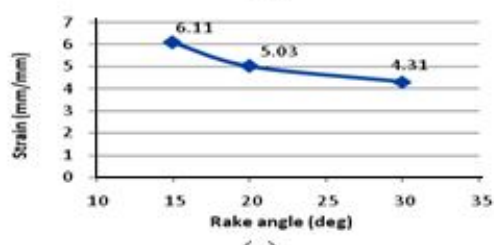

(c)

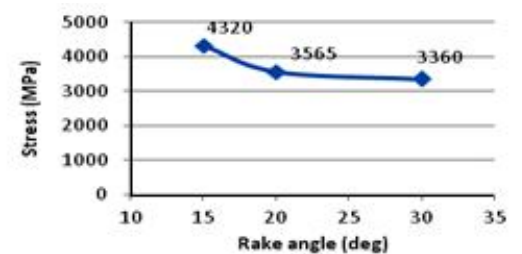

(b)

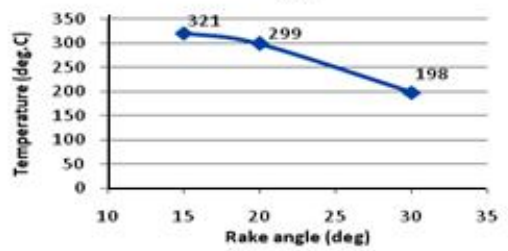

(d)

Fig. 5 Effect of rake angle, (a). rake angle vs cutting force, (b). rake angle vs stress, (c). rake angle vs strain, and (d). rake angle vs

The Effect of Clearance Angle $(\gamma)$. The increase of clearance angle does not much influence the cutting force, stress, strain and generated temperature as shown in Fig. 6a, 6b, 6c, and 6d. All of these results were also agreeable with the theory, because the change of clearance angle will not affect the cutting force and stress, but the increase of clearance angle only affects slightly on the wear rate. Clearance angle will affect wear and tool life of the cutting tool because the clearance 
face will rub against the freshly cut metal surface. In industry, the clearance angle is varied, but often in the order of $6-10 \mathrm{deg}[11]$.

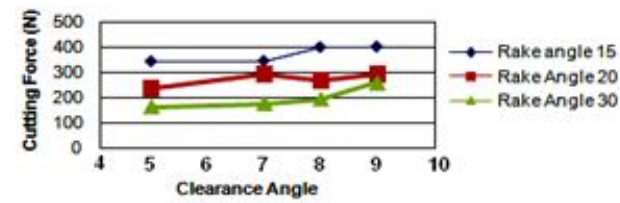

(a)

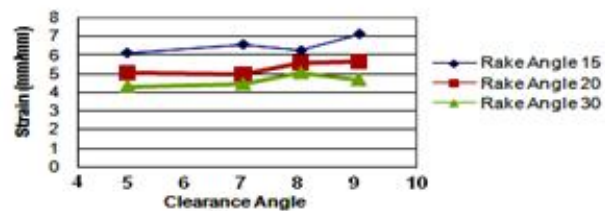

(c)

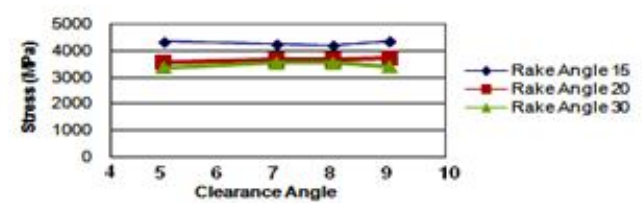

(b)

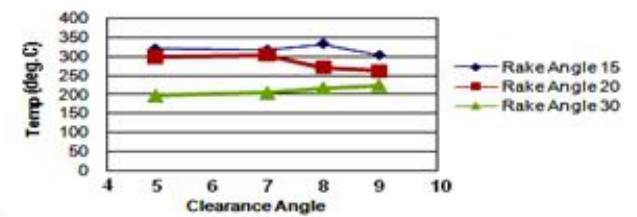

(d)

Fig. 6 Effect of clearance angle, (a) clearance angle vs cutting Speed, (b) clearance angle vs stress, (c) clearance angle vs strain, (d) clearance angle vs temperature.

\section{Conclusion}

The distribution of cutting force, effective stress and generated temperature obtained from simulations are agreeable with the results given in literature. From the simulation, it can be concluded that increasing the rake angle $(\alpha)$ in the turning of ductile cast iron using tungsten carbide $(\mathrm{CW})$, it will improves the machining performance by reducing the cutting force, stress, strain and generated temperature. But, by increasing the clearance angle $(\gamma)$, it will not influence much to the cutting force, stress, strain and generated temperature on chip.

\section{References}

[1] T.D. Marusich and Ortiz: Modeling and Simulation of High-Speed Machining, To appear: International Jour. Num. Metallurgy Engineering. (1995).

[2] A. E. Cerenitti, B.P. Fallbohmer, W. Wu C.W and Altan B.T: Application of 2D FEM to Chip Formation in Orthogonal Cutting, Jour. of materials Processing Technology Vol. 59 (1996), p.169-180.

[3] J. Q. Xie, A. E. Bayoumi, and H. M. Zbib: FEA Modelling and Simulation of Shear Localized Chip Formation in Metal Cutting, Jour. of Materials Processing Technology Vol. 38 (1998), p.1067-1087.

[4] C. Shet: Finite Element Analysis of the Orthogonal Metal Cutting Process, Jour. of Materials Processing Technology Vol. 105 (2000), p. 95-109

[5] A.E.Cerenitti, C.Lazzaroni, L.Menegardo and B.T.Altan: Turning Simulation Using a ThreeDimensional FEM Code, Jour. of materials Processing Technology Vol. 98 (2000), p.99-103.

[6] O.H.Columbus, in : Deform ${ }^{T M}-3 D$ Machining (Turning) Lab, Scientific Forming Tech. Corporation (2007).

[7] J. Mackerle: Finite Element Analysis and Simulation of Machining: a Bibliography (1976 1996), Jour. of Materials Processing Technology Volume 86 (1999), p. 17-44.

[8] P. L. B. Oxley, in: Mechanics of Machining: An Analytical Approach to Assessing Machinability, Ellis Horwood, Chichester, West Sussex (1989), p. 223-227

[9] V. Kalhori, in: Modelling and Simulation of Mechanical Cutting, Doctoral Thesis, Institutionen for Maskinteknik, Sweden (2001).

[10] M. G. Gunay, I. Korkut, E. Aslan and U. S. Eker: Experimental investigation of the effect of cutting tool rake angle on main cutting force, Jour. of Materials Processing Technology Vol. 166 (2005), p. 44-49.

[11] E. M. Trent, in: Metal Cutting, Butterworth - Heinmann Ltd, London (1991). 


\section{Editorial Board}

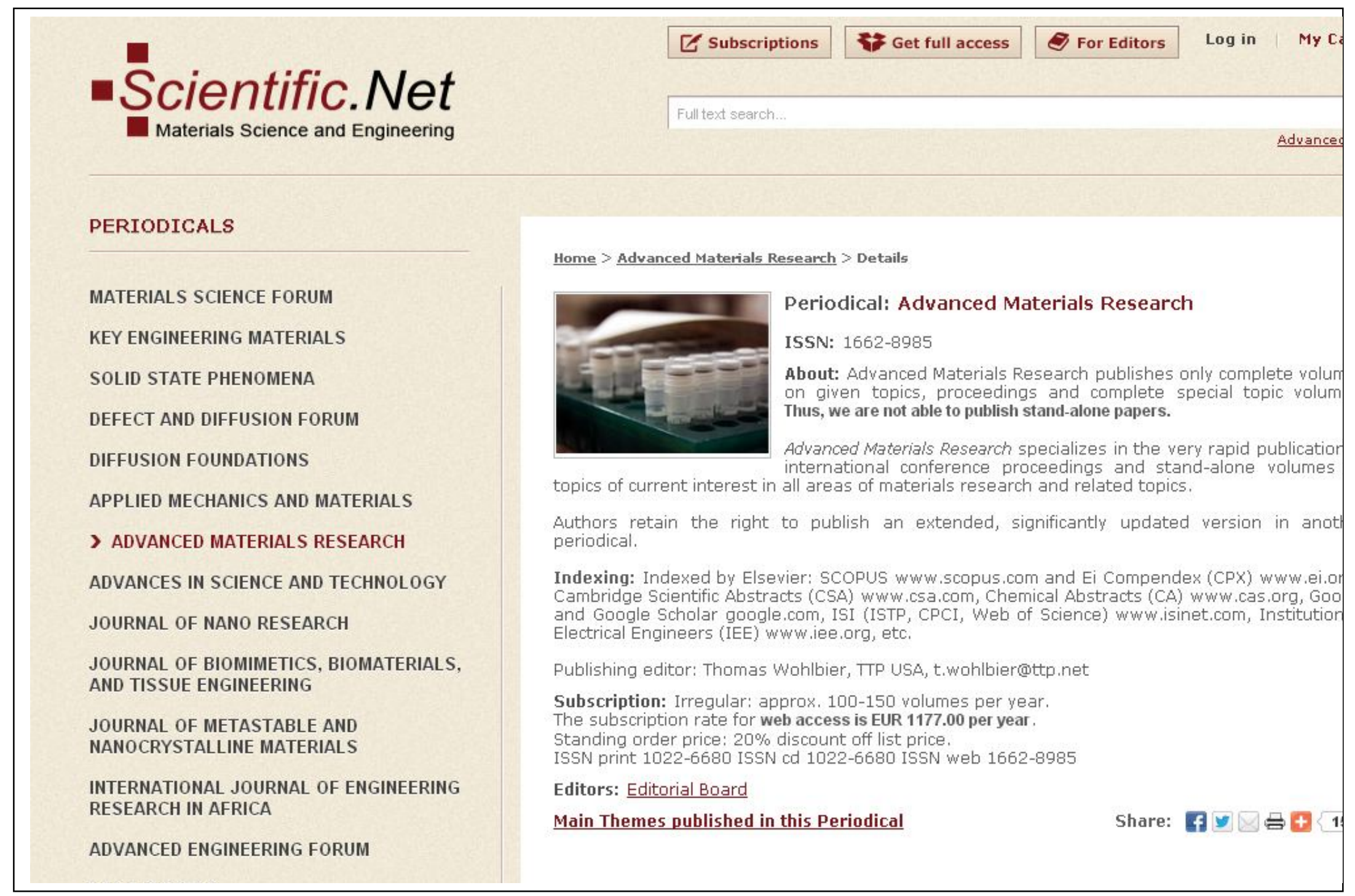




\section{Editors}

$\mathrm{Hu}, \mathrm{X} . \mathrm{Z}$.

The University of Western Australia, School of Mechanical and Chemical Engineering; Applied Mechanics \& Advanced Materials Group, Perth, Australia, WA 6009;

Lau , A.K.T.

Send mail

Hong Kong Polytechnic University, Department of Mechanical Engineering; Hung Hom, Kowloon, Hong Kong, China;

Publishing Editor Wohlbier, T.

Send mail

105 Springdale Lane, Millersville, United States of America, PA 17551;

\section{Editorial Board}

Barton , J.

Send mail

University of Southampton, School of Engineering Sciences; Highfield, Southampton, United Kingdom, SO17 1BJ;

Cao, P.

Send mail

University of Waikato, Department of Materials and Process Engineering, Waikato Centre for Advanced Materials; Private Bag 3105, Hamilton, New Zealand, 3240;

Chandra, T.

Send mail

University of Wollongong, Faculty of Engineering, School of Mechanicals, Materials and Mechatronic Engineering; 33 Bootie

Street, Wollongong, Australia, NSW 2522;

Chicinaş, I.

Technical University of Cluj-Napoca, Department of Materials Science and Technology; 103-105 Muncii Blv., Cluj-Napoca,

400641, Romania;

Daniel , B.S.S.

Send mail

Indian Institute of Technology Roorkee, Department of Metallurgical and Materials Engineering, Centre of Nanotechnology; Roorkee, India, 247667

Engel, U.

Send mail

Friedrich-Alexander-Universität Erlangen-Nürnberg, Chair of Manufacturing Technology; Egerlandstrasse 11-13, Erlangen,

91058, Germany;

Evans, S.L.

Send mail

Cardiff Universitv. Cardiff School of Enaineerina: Oueen's Buildinas. P. O. Box 925 Parade. Newnort Road. Cardiff. United

Dalian University of Technology, School of Mechanical Engineering; Dalian, Liaoning, China, 116024

bhadode, A.O.A.

Send mail

University of Benin, Department of Production Engineering, Faculty of Engineering; Benin, Nigeria; 
Jha , P.K.

Send mail

Bhavnagar University, Department of Physics; Bhavnagar, India, 364001;

Kim , J.K.

Send mail

Hong Kong University of Science and Technology, Department of Mechanical Engineering; Clear Water Bay, Pokfulam Road Kowloon, Hong Kong, China:

Leng , J.S.

Send mail

Harbin Institute of Technology, Center for Composite Materials and Structures; BLDG. A, Science Park of Harbin Institute of Technology, No. 2 Yikuang Street Nangang DIST., Harbin, Heilongjiang, China, 150080;

Palkowski , $\mathrm{H}$.

Send mail

Clausthal University of Technology, I nstitute of Metallurgy; Robert-Koch-Strasse 42, Clausthal-Zellerfeld, 38678, Germany;

Pullin, R.

Send mail

Cardiff University, Cardiff School of Engineering; Queen's Buildings, P.O.Box 925 Parade, Newport Road, Cardiff, United

Kingdom, CF24 3AA

Sand, W.

Send mail

University of Duisburg-Essen, Biofilm Centre, Aquatic Biotechnology; Geibelstrasse 41, Duisburg, 47057, Germany;

Schikorra, M.

Send mail

Technical University of Dortmund, Institute of Forming Technology and Lightweight Construction (IUL); Baroper Street 301

Dortmund, 44227, Germany;

Yin, Y.S.

Send mail

Shanghai Maritime University, Institute of Marine Materials Science and Engineering; 1550 Harbor Ave, Lingang New City,

Shanghai, China, 200135;

Zhang , D.L.

Send mail

University of Waikato, Waikato Centre for Advanced Materials (WaiCAM), School of Engineering; Private Bag 3105, Hamilton, New Zealand, 3240;

Zhang , T.Y.

Send mail

Hong Kong University of Science and Technology, Department of Mechanical Engineering; Clear Water Bay, Pokfulam Road Kowloon, Hong Kong, China; 



\section{PAPER TITLES}

Tool Life in High Speed Turning with Negative Rake Angle, p.1009

Effect of Process Parameters on Abrasive Contamination during Water Abrasive Jet Machining of Mild Steel, P.1015

Experimental and FEM Study of Serrated Chip Formation in High Speed Turning Processes, P.1021

Chemical Wet Etching of Silicon Wafers from a Mixture of Concentrated Acids, p.1027

> Application of FEM in Investigating Machining Performance, P.1033

Numerical, Analytical and Experimenta Study of Structural Properties of Cutting Tool in Endmilling Process, P.1039

Surface Integrity of AISI H13 in End Milling and Electrical Discharge Machining Process, p.1044

Evaluation of PVD-Inserts Performance and Surface Integrity when Turning Ti-6 AI-4V ELI under Dry Machining, p.1050

Study of Micro-EDM of Tungsten Carbide with Workpiece Vibration, P.1056
Home $>$ Advanced Materials Research $>$ Advances in Materials and Processing Technologies... > Application of FEM in Investigating Machining...

\section{Paper Title: Application of FEM in Investigating Machining Performance}

\begin{tabular}{|c|c|}
\hline Periodical & $\frac{\text { Advanced Materials Research (Volumes } 264 \text { - }}{265 \text { ) }}$ \\
\hline Main Theme & $\begin{array}{l}\text { Advances in Materials and Processing } \\
\text { Technologies II }\end{array}$ \\
\hline Edited by & M.S.J. Hashmi, S. Mridha and S. Naher \\
\hline Pages & $1033-1038$ \\
\hline DOI & $10.4028 / w w w . s c i e n t i f i c . n e t / A M R .264-265.1033$ \\
\hline Citation & $\begin{array}{l}\text { Hendri Yanda et al,, 2011, Advanced Materials } \\
\text { Research, 264-265, } 1033\end{array}$ \\
\hline Online since & June, 2011 \\
\hline Authors & $\begin{array}{l}\text { Hendri Vanda, Jaharah A. Ghani, Che Hassan Che } \\
\text { Haron }\end{array}$ \\
\hline Keywords & $\begin{array}{l}\text { Clearance Anqle, Finite Element Model (FEM), } \\
\text { Machining Performance, Rake Angle }\end{array}$ \\
\hline Price & US $\$ 28,-$ \\
\hline
\end{tabular}

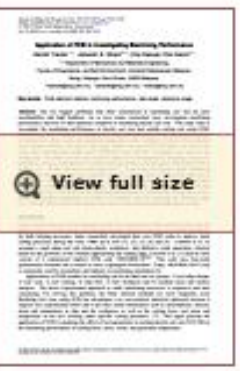

\section{Abstract Related Articles}

The two biggest problems that often experienced in machining cast iron are poor machinability and high hardness. Up to now, many researchers have investigated machining performance and how to find optimum condition in machining ductile cast iron. This study aims to investigate the machining performance of ductile cast iron and carbide cutting tool using FEM. Performances were evaluated by changing the cutting tool geometries on the machining responses of cutting force, stress, strain, and generated temperature on the workpiece. Deform-3D commercial finite element software was used in this study. Ductile cast iron FCD 500 grade was used as the work piece material and carbide insert DNMA 432 type with WC (Tungsten) was used for the cutting tool. The effects of rake and clearance angles were investigated by designing various tool geometries. Various combination of carbide insert geometries were designed using Solid Work to produce $+15,+20$ and +30 deg for rake angle and $5,7,8$ and 9 deg for clearance angle. Machining condition for the simulations were remained constant at cutting speed of $200 \mathrm{~m} / \mathrm{min}$, feed rate of $0.35 \mathrm{~mm} / \mathrm{rev}$, and depth of cut of $0.3 \mathrm{~mm}$. The results of effective-stress, strain and generated temperature on both chip and material surface were analysed. The results show that by increasing the rake angle ( $a$ ), it will improves the machining performance by reducing the cutting force, stress, strain and generated temperature on surface of workpiece. But, by increasing the clearance angle ( $\mathrm{V}$ ), it will not affect much to the cutting force, stress, strain and generated temperature on chip. 



\section{DAFTAR ISI}

TENSILE AND DYNAMIC MECHANICAL BEHAVIOR OF THERMOPLASTIC NATURAL RUBBER (TPNR) NANOCOMPOSITES TREATED WITH ULTRASONIC

Mou'ad.A.Tarawneh, Sahrim Hj. Ahmad, S.Y.Yahya and Rozaidi Rasid

Optimization of Process Parameters on EDM Milling of Stainless Steel AISI 304 1001

AKM Asif lqbal and Ahsan Ali Khan

PARETO OPTIMIZATION OF ELECTRO DISCHARGE MACHINING

1007

OF TITANIUM NITRIDE-ALUMINIUM OXIDE COMPOSITE

MATERIAL USING GENETIC ALGORITHM

Souren Mitra, Soumya Sarkar, Goutam Paul, D.Bhaduri, Sampad Biswas

Sensing Tool Breakage in Face Milling By Support Vector Machine

1019

Yao-Wen Hsueh1, a and Chan-Yun Yang2,b

Optimization of Precision Grinding Parameters of Silicon for Surface

1025

Roughness Based on Taguchi Method

Alao Abdur-Rasheed and Mohamed Konneh

NEW APPROACH IN COST STRUCTURING OF HIGH SPEED HARD

TURNING

Muataz Al Hazza, Erry Yulian T. Adesta, Delvis Agusman, Agus Geter E.

Sutjipto, Muhammad Riza

Tool Life in High Speed Turning With Negative Rake Angle

Erry Yulian T. Adesta, Muataz Al Hazza, Delvis Agusman, Muhammad Riza,

Afifah Mohd Ali

Effect of Process Parameters on Abrasive Contamination during Water

Abrasive Jet Machining of Mild Steel

Afifah Mohd Alia, Ahsan Ali Khanb, Mohammad Yeakub Ali

EXPERIMENTAL AND FEM STUDY OF SERRATED CHIP FORMATION IN HIGH SPEED TURNING PROCESSES

U.Umer, L. Xie, SJ. Askari, S.N. Danish, S.I. Butt

CHEMICAL WET ETCHING OF SILICON WAFERS FROM A MIXTURE OF CONCENTRATED ACIDS

M. R. Ismail1, W. 1. Basirun

Application of FEM in Investigating Machining Performance

1061

Hendri Yanda, Jaharah A. Ghani and Che Hassan Che Haron

Numerical, Analytical and Experimental Study of Structural Properties of

Cutting Tool in Endmilling Process

M.Mahdi Abootorabi Zarchi, Hamed Zoghi and M. Reza Razfar

SURFACE INTEGRITY OF AISI H13 IN END MILUNG AND ELECTRICAL

DISCHARGE MACHINING PROCESS

Jaharah A.Ghani, Goh GokYeong and Che Hassan Che Haron

Evaluation of PVD-Inserts Performance and Surface Integrity When 



\section{SClmago \\ Journal \& Country \\ Rank}

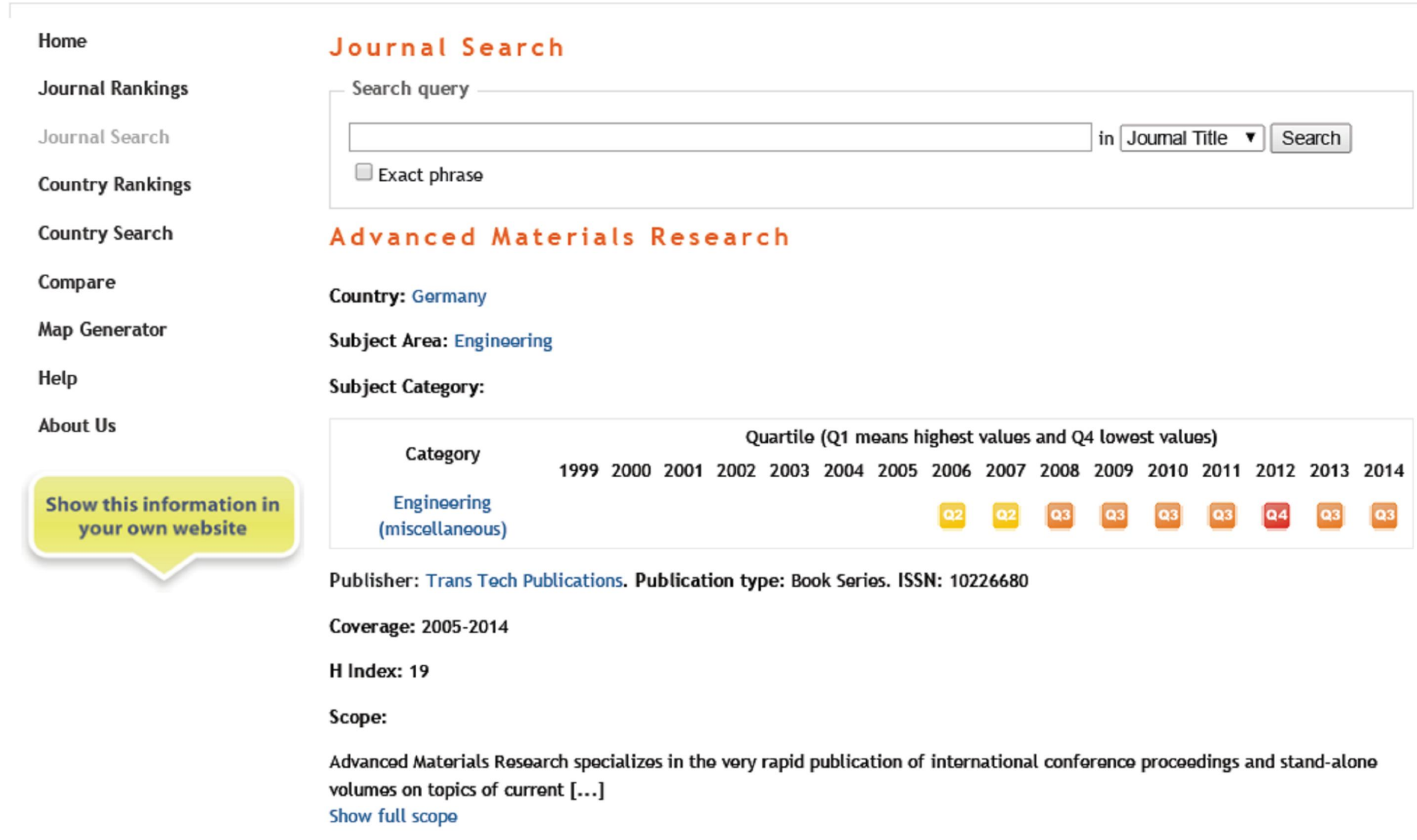

